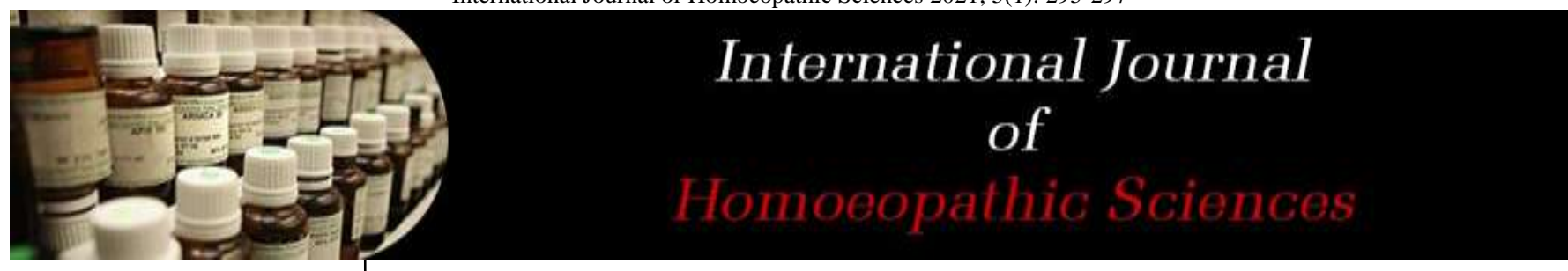

E-ISSN: $2616-4493$ P-ISSN: 2616-4485 www.homoeopathicjournal.com IJHS 2021; 5(1): 295-297 Received: 15-12-2020 Accepted: 23-01-2021

Dr. Priyanka Jotiram Chavan Department of Homeopathic Repertory, GMHMC, Jalna, Maharashtra, India
Corresponding Author: Dr. Priyanka Jotiram Chavan Department of Homeopathic Repertory, GMHMC, Jalna, Maharashtra, India

\section{Understanding the rubric indifference and the first grade remedies of Kent's repertory}

\author{
Dr. Priyanka Jotiram Chavan \\ DOI: $\underline{\text { https://doi.org/10.33545/26164485.2021.v5.i1e.329 }}$
}

\begin{abstract}
Repertory is an index to the materia medica, where we find the symptoms along with the remedies present under a specific rubric at one place. Majority of the rubrics found in the mind. Individualisation is the core concept of homoeopathy and according to these understood how the remedies differ for that particular rubric and also differentiate the 1 st grade remedies in the kent's repertory.
\end{abstract}

Keywords: Understand homoeopathic rubrics, remedy analysis, apis melifica, china, helleborus, natrum carb, natrum mur, opium, phosphoric acid, phosphorous, pulsatilla, kent's repertory

\section{Introduction}

Homeopathy is a system of medicine which is based on the principle "similia similibus curentur". A physician with his knowledge and experience establishes a similarity between the individual with the disease and the medicine. Repertory is an index to the materia medica, where we find the symptoms along with the remedies present under a specific rubric at one place. Majority of the rubrics found in the mind are neglected by the common practitioners for want of correct understanding and right interpretation of the rubrics.

For successful use of the repertory the meaning of the rubrics should be well understood and also the understanding of how the remedies differ for that particular rubric should be known, as the core concept of homoeopathy is individualisation. Keeping this in mind an attempt is made to understand the meaning of the rubric "indifference" and also differentiate the $1^{\text {st }}$ grade remedies from Kent's repertory.

\section{Indifference}

Marked by total or negligible important or value for something - no marked feeling, interest or concern. Neutrality of mind between persons or things. There is a lack of interest, sympathy or anxiety towards either children or business matters or loved ones or some doing.

According to webster's dictionary Indifference - it is the Lack of feeling for or against anything; apathy; lack of sufficient importance to constitute a difference; not easily interested or moved; neither good or bad, desirable or undesirable It is also a sickness arising from total physical collapse or mental shock, with no strength to care. Sometimes it is part of a curative process-offering the individual a way to find emotional equilibrium or overcome an underlying vulnerability.

The rubric indifference in Kent's repertory has $91^{\text {st }}$ grade remedies -3 marks

1. Apis Mellifica

2. China officinalis

3. Helleborous

4. Natrium carbonicum

5. Natrium muriaticum

6. Opium

7. Phosphoric acid

8. Phosphorous

9. Pulsatilla

\section{Apis Melifica}

1. Absolutely indifferent to everything that would make her happy or joyful. 
2. Aggravation in heat and in warm room. Ailments from fright, rage, vexation, jealousy or hearing bad news. Busy insanity - patient is constantly busy doing things. Strong tendency to jealousy.

3. Foolishly jealous and suspicious, absolutely joyless.

4. No ability to apply things that would make her happy to herself, they must mean someone else.

5. Lost all consciousness of things around him, and sank into a state of insensibility.

6. There is Dulness of mind causing Difficulty in thinking. The patient is unable to bring his thoughts to anything definite. In typhus when asked if sick, he says: nothing is the matter, lies in a soporous condition, unconscious, with delirious muttering and hardness of hearing.

\section{China}

Indifference follows a debilitating physical illness, where the patient simply has too little energy to care. The patient becomes indifferent, apathetic, low spirited, silent, and disinclined to think. He is unable to control themind, to make it do what it wants to do. Indifference arises from extreme debility-great lassitude and weakness, usually associated with the loss of vital fluids (haemorrhages, drenching perspiration, diarrhoea). It can also result from severe mental shock-after a fright or overwhelming sorrow. There is indifference to eating and drinking.

\section{Helleborus}

Depression, apathy and perfect indifference, wholly indifferent to his fate, he cares not whether he lives or dies. Stubborn silence When questioned, answers slowly; stupefaction bordering on insensibility. Diminished power of mind over body, they cannot fix ideas and slow in answering. Indifference after injury to head. Indifference after typhoid which causes mental dejection and apathy. Dull and indifferent to all external impressions, will not speak, sits quietly in bed and seems lost in brooding, will take proffered food but never expresses desire for anything.

\section{Natrum Carb}

Misanthropy - aversion to mankind, aversion to society and indifference to one's own family. Aversion to relatives, to strangers; feels a great division between himself and them. Indifference to business and friends, excessively irritable, doesn't tolerate anyone talking to her. Music causes a tendency to suicide, melancholy, weeping and trepidation which increases to religious insanity. Playing the piano is so exhausting that she must lie down. Depressed and irritable, accompanied by gastric symptoms.

\section{Natrum Mur}

Indifference is born of hopelessness and mental languor. Individuals are very emotional and sensitive and they feel any form of rejection, ridicule, humiliation or grief would be personally intolerable. Consequently, they create a wall of invulnerability, become enclosed in their own worlds, and prefer to maintain control over their circumstances. They avoid being hurt at all costs. After being hurt several times, they learn to become cautious. They will think twice before becoming involved in an emotional experience. They turn to introverted activities which are emotionally "safe", i.e reading books, listening to music, dwelling on ideas and fantasies. They can become quite content in their isolation. They tend to be self-contained, desiring to solve problems by themselves without trusting help from other people. Gradually, they come to the point of not needing contact with the outside world. If someone intrudes upon their private, introverted world, they may feel resentful. Their primary concern in life becomes, "not to hurt and not to be hurt". Sad and tearful. No matter how cheering the circumstances are she cannot bring herself into the state of being joyful. She is benumbed to impressions, easily takes on grief, grieves over nothing. Unpleasant occurrences are recalled that she may grieve over them. Consolation aggravated the state of the mind - the melancholy, the tearfulness, sometimes brings on anger.

\section{Opium}

Indifference to everything. Rash and inconsiderate, vivid imagination. Stupid indifference Unable to understand or appreciate his sufferings. Thinks he is not at home. Ailments from fright. Complaints of nothing, wants nothing.

\section{Phosphoric Acid}

They are indifferent to the affairs of life. Prostrated and stupefied with grief. Indifference to those things that used to be of most interest, especially if accompanied by debility and emaciation. When questioned he answers slowly or does not speak, but only looks at the questioner. He is too tired to talk or even think. This state is found in both acute and chronic diseases. In chronic diseases ailment from - long study, prolonged worry in businessmen, in feeble school girls. In acute diseases it is usually seen in typhoid fever. The patient is averse to speaking or answering questions, He merely looks. Finally he rouses up and says: "Don't talk me, I am so tired." He cannot think what he wishes to say, cannot frame his answers to questions. Another cause is sexual excesses in young men, or in those guilty of secret vice. Ailments from grief, disappointed affection, chagrin, loss of vital fluids, violent acute diseases.

\section{Phosphorous}

Patient is usually emotional, loving, sympathetic and caring in nature. Becomes easily excited, anxious fearful and restless, then a phase of indifference, apathy, weakness of memory and dullness of senses occurs. Indifference is towards loved ones, family and surroundings because he does not get the love and attention he wants from family members. There is indifference to own children. Answers no questions, takes no notice of his family and things about him, answers slowly, thinks sluggishly, seems dazed or in a stupor. Everything looks dark, he is weary of life, gloomy and says nothing. Patient becomes weepy, sad, and hysterical; Self centred and inconsiderate. Mentally, the patient easily forgets himself, even to the degree that awareness can become too diffuse and unfocused; the patient becomes easily "spaced out". All the mental symptoms are worse from mental exertion; aggravated from noise.

\section{Sepia}

Sepia's natural independence sets her apart from other women. She seeks to be herself, unfettered by the expectations of others, especially those of men. They are free spirited and irritable. They do not like to be dominated and when they are not allowed to be independent and she is forced to do things against her will. This makes her feel unfortunate and disturbs her emotional, intellectual or 
physical levels. Hence in emotional level we find apathy, indifference. We find aversion to one's family and work. Indifference to loved ones - family, husband, kids etc. The indifference is more towards people who have brought her the sadness. The remedy seems to abolish the ability to feel natural love, to be affectionate. To illustrate it in the language of the mother: "I Know I ought to love my children and my husband, I used to love them, but now I have no feeling on the subject." There is a lack of realization, a lack of ability to register such affections; the love does not manifest itself. Very indifferent to everything: the death of a near relative or some happy occurrence leave her equally unaffected. This state is brought out in a woman during confinement, after uterine and other haemorrhages, after prolonged indigestion; high living with disturbance in the circulation, pallor, enfeeblement of body and mind. It can also be seen in men, but it is a striking feature in the woman. It often comes on when nursing a child, from nursing an over-vigorous child or twins who require much lacteal fluid and this drags her down. It may be brought out in a woman who has an over-vigorous husband. Excessive sexual excitement and over-indulgence brings on coldness and she becomes a cold woman. She who has been excitable, nervous, and fidgety becomes the opposite, taking on a stoical state of mind. An absence of all joy, inability to realize that things are real; all things seem strange; no affection for the delightful things of life; life has nothing in it for her.

\section{Pulsatilla}

Pulsatilla's indifference is to business affairs, characterized by indecisiveness. There is no clear reason for choosing one preference, one course of action, over another. This goes hand-in-hand with the conviction that if she waits long enough, assistance will be forthcoming. Indifference to her household affair, to which she was formerly attentive. She seeks consolation. Changeable - Irritable once, tearful again, mild pleasant and again tearful. Emotional satisfaction is the cornerstone of pulsatilla. She imagines the company of the opposite sex a dangerous thing to cultivate, and that it is dangerous to do certain things well established in society as good for the human race. She will not answer questions unless hard pressed, when all she will say is "Yes" or "No", or she will merely shake her head.

\section{Conclusion}

Repertory is a useful tool, wherein we find symptoms in the form of rubrics and a group of medicines known to produce it or associated with it. It gives an idea about the close running medicines.

Success in homoeopathic prescription lies in the ability to individualise of the physician to individualise the patient and also in differentiating a group of similar remedies, thereby arriving at the similimum.

\section{References}

1. Kent J. Repertory of the homoeopathic materia medica. New Delhi: B. Jain Publisher 1961.

2. Kent J. Lectures on homoeopathic materia medica. 1st ed. New Delhi: B. Jain Publisher 1998.

3. Hering $\mathrm{C}$. The guiding symptoms of our materia medica. $1^{\text {st }}$ ed. New Delhi: B. Jain 1974.

4. Clarke J. A dictionary of practical materia medica. 1st ed. New Delhi, India: B. Jain; 1995.
5. Phatak S. Materia medica of homoeopathic medicines. 2nd ed. New Delhi: B. Jain publishers 1999.

6. Vithoulkas G. Materia medica viva. London: Homeopathic Book Publishers 1995.

7. Bailey P. Homeopathy psychology. 1st ed. New Delhi: B.Jain publishers 2002.

8. Kent JT. Lectures on Homeopathic Philosophy (Lecture 33). New Delhi, India: B Jain 1991, 213-214.

9. Farrington E. Lecture on Clinical Materia Medica. New Delhi: B. Jain Publisher (P) Ltd 2002.

10. Khedekar S, Upadhyay C. Acsotrom. $1^{\text {st }}$ ed. New delhi: Indian Books \& Periodicals Syndicate 2003.

11. Homeopathic material medica-William boericke.

12. Roberts HA. The principles and art of cure by homoeopathy, Indian journal of homoeopathic sciences, Dr. Yashika arora 2018, 2.

13. Tiwari SK. Essential of Repertorisation, Fifth Edition, Narayana Verlag, Germany 2012.

14. JT. Repertory of Homoeopathic Materia Medica, $6^{\mathrm{TH}}$ American Edition, B Jain Publishers Pvt Ltd, New Delh-110055

15. Phatak SR. A Concise Repertory of Homoeopathic Medicines, (Revised and Enlarged $4^{\text {th }}$ Edition), B Jain Publishers Pvt Ltd. Adi BS. Efficacy of homoeopathic medicines in chronic low back pain: a clinical study. International Journal of Alternative and Complementary Medicine. 2020, 17-20. New Delhi110055.

16. Knerr C, Hering C. Repertory of Hering's guiding symptoms of our Materia Medica. 1st ed. Philadelphia: F.A. Davis Co. 1896.

17. Boericke W. New manual of homoeopathic materia medica and repertory. New Delhi: Kuldeep Jain for B. Jain Publishers 2003.

18. Lilienthal S. Homoeopathic therapeutics, The classical therapeutic Hints. 24th ed. New Delhi: B. Jain 2016.

19. Clarke J. Dictionary of materia medica. Essex, England: Health Science Press 1982.

20. Tiwary, Shashi Kant. Essentials of Repertorisation, 5th edition, B. Jain Publishers Pvt. Ltd., 25 ${ }^{\text {th }}$ impression 2014.

21. William Gentry D. The Concordance Repertory of the More Characteristic Symptoms of the Materia Medica; A. L. Chatterton \& Co. Maiden Lane 1892, 78. 